\title{
GROSS ANATOMY OF DURAL SINUSES IN SHEEP
}

R. Merih Hazıroğlu'

Ismet Takcı ${ }^{2}$
Nejat Ciftçi ${ }^{3}$

Koyunda sinus durae matris'in makro anatomisi

Summary: The macro anatomy of dural sinuses in the head ( $n: 30)$ of whitekaraman native breed sheep obtained from an local abattoir was examined. The dorsal system of dural sinuses was consisted of the dorsal sagittal sinus, straight sinus, transverse sinus, temporal sinus and sigmoid sinus. The ventral system of dural sinuses composed of the cavernous sinus, intercavernous sinus, dorsal petrosal sinus, ventral petrosal sinus and basilar sinus. The lacunae laterales were present at the dorsal cerebral veins in which entered to the dorsal sagittal sinus. The straight sinus emptied in the dorsal sagittal sinus shortly before the formation of confluence of sinuses ( $n: 21)$ or in the transverse sinus on the occasion of nine cases. There was intracranial connection between dorsal and ventral system of dural sinuses. The anterior cavernous sinus was present together with posterior cavernous sinus in six cases. The basilar sinus was continued as the ventral internal vertebral plexus inside the vertebral canal.

Özet: Ankara Et ve Balık Kurumu Mezbahasindan temin edilen 30 adet Akkaraman koyun basında sinus durae matris'in makro anatomisi incelendi. Dorsal sinus sisteminin sinus sagittalis dorsalis, sinus rectus, sinus transversus, sinus temporalis ve sinus sigmoideus'tan, ventral sinus sisteminin ise sinus cavernosus, sinus intercavernosus, sinus petrosus dorsalis, sinus petrosus ventralis ve sinus basilaris'ten oluştuğu görüldü. Vv. cerebri dorsales'in sinus sagittalis'e açıldığı yerde lacunae laterales'in varlı̆̆ı dikkati çekti. Sinus rectus'un sinus sagittalis dorsalis'e ( $n:$ 21) ya da sinus transversus'a ( $n:$ 9) açıldı̆̆ görüldü. Dorsal ve ventral sinus sistemi arasında iliskinin varlığı saptandı. Altı olguda sinus intercavernosus caudalis ile birlikte sinus intercavernosus rostralis'in bulunduğu gözlendi. Sinus basilaris'in caudal ve ventral'de plexus venosus vertebralis internus şeklinde devam ettiği görüldü.

\section{Introduction}

The dural sinuses mostly located intracranially between dura mater's periosteal and meningeal parts. Generally they lack tunica media in their walls, and

1. Doç. Dr., A.Ü. Vet. Fakültesi, Anatomi Anabilim Dalı, Ankara.

2. Araş. Gör. Dr., KA.Ü.Vet.Fak., Anatomi Anabilim Dalı, Kars.

3. Araş.Gör.Dr., A.Ü.Vet.Fak., Anatomi Anabilim Dalı, Ankara. 
they do not have valves in their lumina. The dural sinuses are divided into dorsal and basilar systems. The dorsal system consists of dorsal sagittal, straight sinuses and transverse sinuses. The basal system consists of the cavernous, inter cavernous, basilar, and dorsal and ventral petrosal sinuses $(3,5,6)$. Anatomic descriptions of these are available for domesticated animals in the standart textbooks $(5,6,14)$. The horse has been used as the basis for anatomic information in these textbooks, but the information on the sheep dural sinuses is very scanty.

The purpose in the present report is to give a gross descriptions of the dural sinuses in whitekaraman sheep.

\section{Material and Methods}

Thirty adult, local breed (whitekaraman) sheep heads were obtained from the local abattoir (The sheep body weights and sexes were not considered). The heads were flushed with normal saline solution. Of these heads, 18 were injected latex (blue) via the external jugular veins, six sheep heads were injected with methylmethacrylate, six sheep head were injected radioopaquae contrast media for venograpy via the external jugular vein.

Specimens injected with latex were dissected and stored in $4 \%$ formalin solution. The other heads were macerated with $33 \% \mathrm{KOH}$ solution for 2 to 3 weeks or $5 \% \mathrm{HCl}$ solution for one week. Schematic illustrations were drawn from the vascular casts.

\section{Results}

\section{Dorsal system of dural sinuses}

The dorsal sagittal sinus (=sinus sagittalis dorsalis) (Figs. la, 3b, 4A a) was formed by the confluence of right and left external ethmoid veins leaving ophthalmic plexus. From near the cribriform plate of the ethmoid bone, it run caudo dorsally in the attached edge of the falx cerebri and terminated into 2 transverse sinuses near the internal occipital protuberance. The dorsal sagittal sinus was measured $6-6,5 \mathrm{~cm}$ in length and $2-3 \mathrm{~mm}$ in width. Six or 7 cerebral veins entered this sinus and lacunae laterales were present (Fig. 3a). It also received the diploic veins of the frontal and parietal bones.

The straight sinus (=sinus rectus) (Figs.1b, 4A b) was formed at the level of splenium corpus callosi by the confluence of the great cerebral veins ventral$\mathrm{ly}$, and the vein of corpus callosum dorsally. It was about 2-2,5 mm in diameter and $8-9 \mathrm{~mm}$ in length. The straight sinus emptied in the dorsal sagittal sinus shortly before the formation of the confluence of sinuses ( 21 cases). Sometimes ( 9 cases) it drained into transverse sinus.

The transverse sinus (=sinus transversus) (Figs. 1c, 4A c) was paired and located inside the membraneous tentorium of cerebellum. It supposed ventrolateral continuation of the dorsal sagittal sinus. It was merged with its fellow to 
form the confluence of the sinuses. This triple merging of sinuses was located within the occipital bone. The transverse sinus occasionally received the straight sinus ( 9 cases). The transverse sinus ran into transverse groove and terminated at the end of this groove. At this point transverse sinus divided into the temporal and sigmoid sinuses.

The temporal sinus (=sinus temporalis) (Fig. 4A d) was larger than sigmoid sinus, continued rostroventrally as the rostral branch of the transverse sinus. It was located with in the temporal canal. It emerged as the emissary vein of the retroarticuler foramen and joined maxillary vein and pterygoid plexus. The temporal sinus was about $2,5 \mathrm{~cm}$ in length and $2,5 \mathrm{~mm}$ in diamater. It anastomosed with the cavernous sinus.

The sigmoid sinus (=sinus sigmoideus) (Fig 4A e) continued caudoventrally as the caudal branch of the transverse sinus. It was " $\mathrm{S}$ " shaped and joined the emissary vein of the condylar foramen. It's branches finally emptied into the occipital vein and basilar sinus.

\section{Ventral system of dural sinuses}

The cavernous sinus (=sinus cavernosus) (Figs. 2c, 4B d) located on both sides of the hypophysis cerebri on the basisphenoidal bone. The carotid rete bathed in the cavernous sinus at the base of the brain. The cavernous sinus was

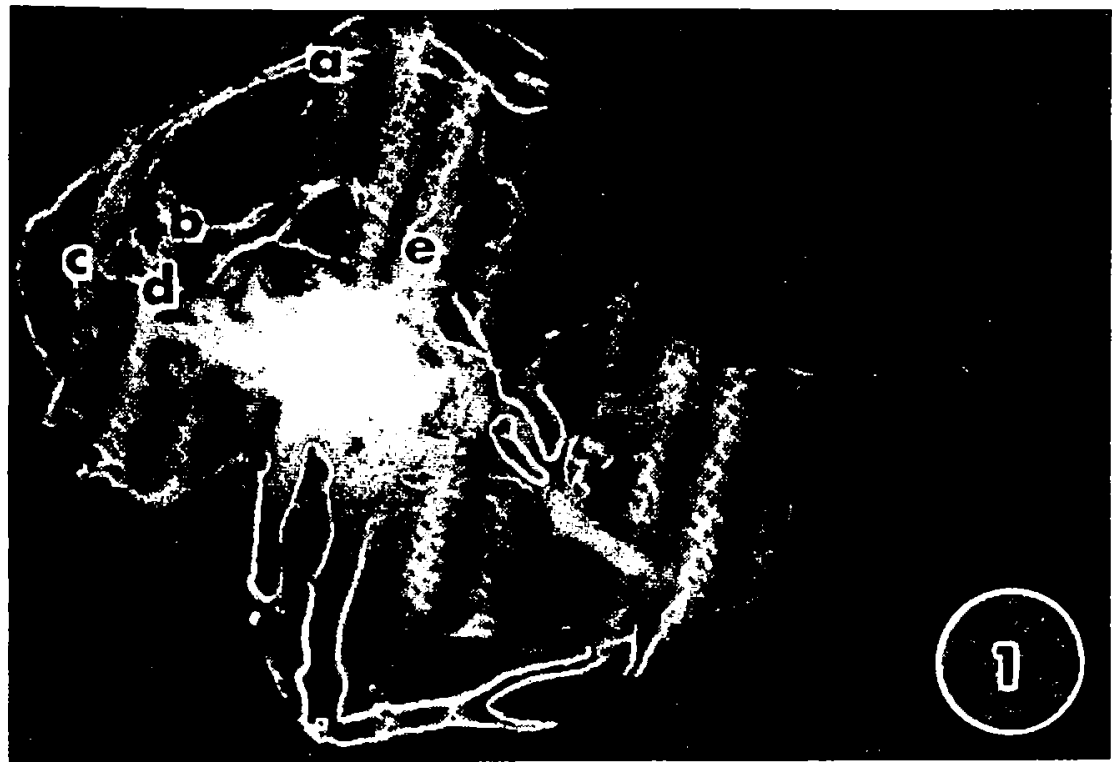

Fig. 1. Lateral view of the venous drainage of the head in the sheep. a)Dorsal sagittal sinus.

b) Straight sinus. c) Transverse sinus. d) Dorsal petrosal sinus. e) Ophthalmic plexus. 


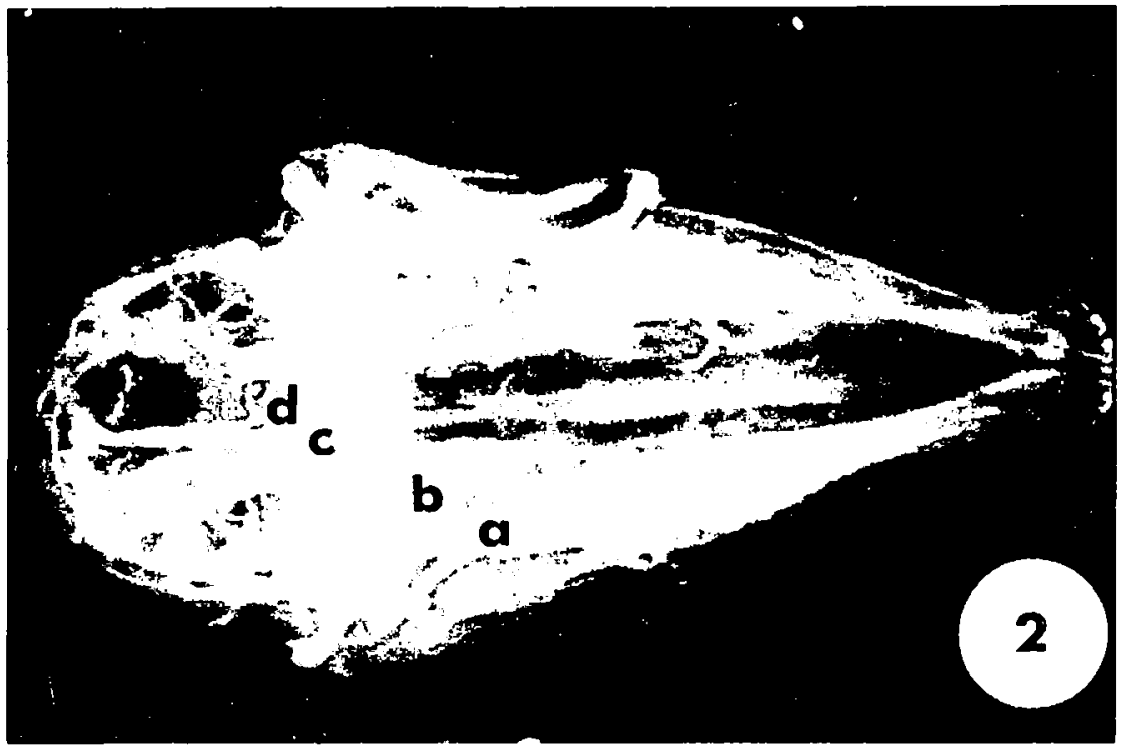

Fig. 2. The cavernous sinus of the sheep-ventral view. a) Angularis oculi v. b) Ophthalmic plexus c) Cavernous sinus. d) Caudal intercavernous sinus.

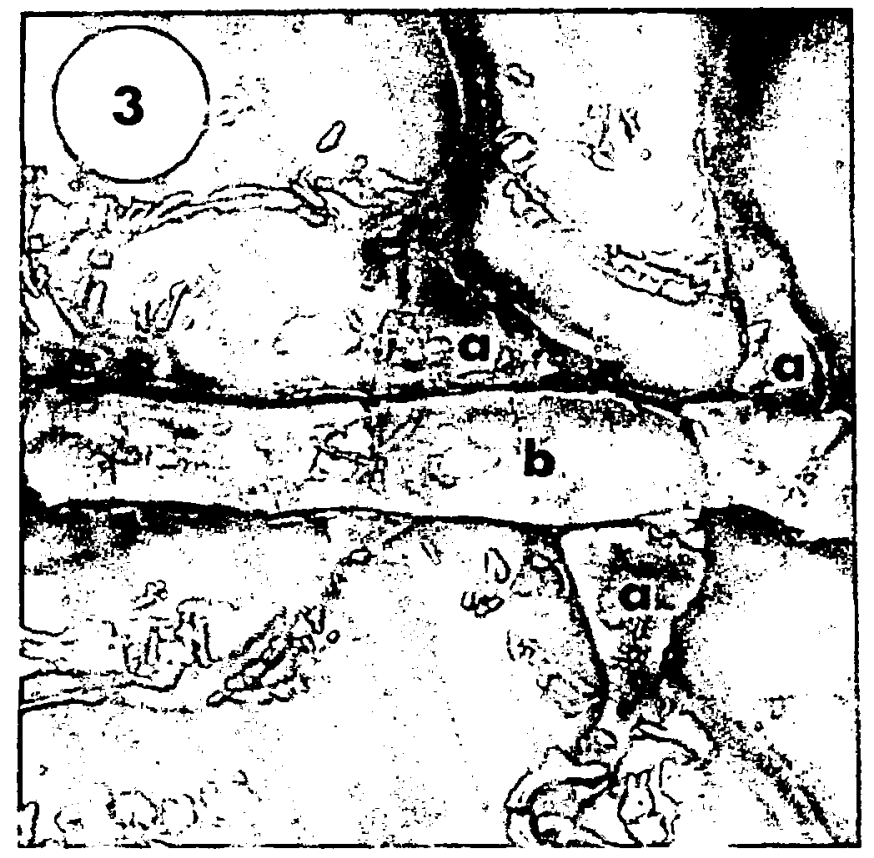

Fig. 3. The dorsal cerebral veins and dorsal sagittal sinus. a) Lacuna lateralıs. b) Dorsal sagittal sinus. 


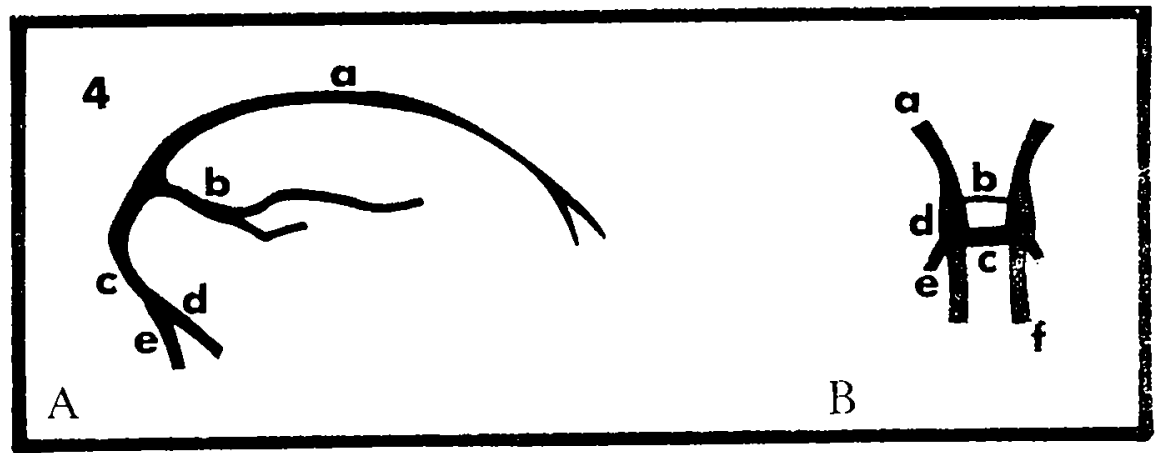

Fig. 4A. Diagram of the dorsal system of dural sinuses-lateral view.

a) Dorsal sagittal sinus. b) Straight sinus. c) Transverse sinus. d) Temporal sinus. e) Sigmoid sinus. 4B. Diagram of the ventral system of dural sinuses-dorsal view. a) Ophthalmic plexus.

b) Rostral intercavernous sinus (inconstantly). c) Caudal intercavernous sinus.

d) Cavernous sinus. e) Dorsal petrosal sinus. f) Basilar sinus.

connected to the ophthalmic plexus (Figs. 1e, 2b, 4B a) via the emissary vein of the orbitorotundum foramen. There was a large venous pathway from the anterior portion of the nasal mucosa to the cavernous sinus [dorsal and lateral nasal veins-angular oculi vein (Fig. 2a), supraorbital vein-opthalmic vein-cavernous sinus]

The right and left cavernous sinuses were transversally connected to each other via a well-developed caudal intercavernous sinus (Figs. $2 \mathrm{~d} 4 \mathrm{~B}$ c) at the caudal aspect of the hypophysis cerebri in all speciemens. There were both rostral and caudal intercavernous sinuses in the six speciemens. The rostral intercavernous sinus (Fig. 4B b) was smaller than those of caudal ones.

Dorsocaudally, the cavernous sinus was connected with the rostral branch of the transverse sinus. This connection could be named as the dorsal petrosal sinus (es) (=sinus petrosus dorsalis) (Figs.1d, 4B e). Caudally the cavernous sinus was continued the basilar sinus.

Ventral petrosal sinus (=sinus petrosus ventralis) was ventrocaudal continuation of the cavernous sinus and connected with the emissary veins of the jugular foramen and the hypoglossal canal. Emissary vein of hypoglossal canal drained into the basilar sinus. The ventral petrosal sinus appeared as the extracranial continuation of the cavernous and basilar sinuses.

The basilar sinus (=sinus basilaris) (Fig. 4B f) was paired and located on the basilar part of the occipital bone. Rostrally, each basilar sinus anastomosed with the cavernous sinus. Caudally the basilar sinus continued as the ventral internal vertebral plexus inside the vertebral canal. There was no interbasilar sinus. The basilar sinus was released to the occipital vein by the emissary vein of the hypoglossal canal. Dorsolaterally, the basilar sinus connected the caudal branch of the transverse sinus (sinus sigmoideus). 


\section{Discussion}

In the whitekaraman native sheep, dorsal system of dural sinuses was composed of the dorsal sagittal, straight, tranverse, temporal and sigmoid sinuses. Dorsal sagittal sinus was formed by the confluence of the right and left external ethmoid veins. It was similar reported results in pigs $(7,8)$. It has been recorded that dorsal sagittal sinus has constructed right and left rhinal veins draining olphactory bulb in dog (13) and camel (16). Dorsal sagittal sinus in dogs arises from the area of the ethmoidal sinuses as the ethmoidal vein entering the skull through one or two foramina (9). The lacunae laterales in horse (5) and dog (1, 5 ) have only been reported but they have not seen in Indian buffalo (12). In this study, it was encountered that lacunae laterales were observed at the dorsal cerebral veins in which entered to the dorsal sagittal sinus.

The straight sinus has been emptied in the dorsal sagittal sinus shortly before the formation of the confluence of sinuses $(3,8,14)$. In our cases, additionally, it was seen that straight sinus was occasionally (n: 9 ) drained to the transverse sinus. This type drainage was also recorded in camels (16).

Intracranial connection has not been reported between dorsal and ventral system in horse $(5,6)$. However, this connection was present in whitekaraman sheep corresponding in camel (16), cattle (15), dog (13) and pig (8). The cavernous sinus was connected with the rostral branch of transverse sinus via the dorsal petrosal sinus and the basilar sinus connected the sigmoid sinus in whitekaraman sheep.

The ventral system of the dural sinuses consisted of the cavernous sinus, intercaviernous sinus, dorsal petrosal sinuts, ventral sinus and basilar sinus in whitekaraman sheep.

The anterior intercavernous sinus is absent in sheep and goats $(5,14)$. The cavernous sinuses are communicated by means of the anterior and posterior intercavernous sinuses on the anterior and posterior of the hypophysis cerebri in cattle $(4,15)$. In this study, the anterior cavernous sinus was present together with posterior cavernous sinus in six cases. These findings were identical to the results of Khamas et al. (10).

Carotid rete baths in the cavernous sinus, therefore, brain temperature is regulated by the cavernous sinuses $(2,10,11,17)$. We also believed that the role of these sinuses are counter current heat exchanger.

In whitekaraman sheep, it was seen that the basilar sinus continued as the ventral internal vertebral plexus inside the vertebral canal. In this point, there is agreement in the literature (16).

As a conclusion, we hope that these results could be beneficial to the concerning researchers with this subject. 


\section{Kaynaklar}

1. Armstrong, L.O., and Morowitz, A. (1971). The brain venous system of the dog. Am. J. Anat., 132: 479-490.

2. Baker, M.A. and Hayward, J.N. (1968). The influence of the nasal mucosa and the carotid rete upon hypothalamic temperature in sheep. J. Physiol., 198: 561-579.

3. Barone, R. and Payan, M. (1976). Drainage veineux de l'encephale et sinus veineux de la dure-mere chez Bos taurus. Revue Méd. vét., 127: 447-458.

4. Boyd, W.H. (1960). The relationship of the cranial dura to the cavernous sinuses in the cow. Anat. Rec., 136: 413-415.

5. Elleberger, W. und Baum, H. (1974). "Handbuch der vergleichenden Anatomie der Haustiere" 18 th ed. Springer Verlag, Berlin.

6. Getty, R. (1975). "Sisson and Grossman's Anatomy of the Domestic Animals" 5th ed., Vol I., W.B. Saunders Company, Philadelphia.

7. Ghoshal, N.G. and Khamas, W.A. (1986). Blood supply of the nasal cavity of the normal pig. Anat. Histol. Embryol., 15: 14-22.

8. Ghoshal, N.G. and Zguigal, H. (1986). Dural sinuses in the pig and their extracranial ve. nous connections. Am. J. Vet. Res., 47: 1165-1169.

9. Hegedus, S.A. and Shackelford, R.T. (1965). A comparative-anatomical study of the craniocervical venous systems in mammals, with special reference to the dog: Relationship of anatomy to measurement of cerebral blood flow. Am.J. Anat., 116: 375-386.

10. Khamas, W.A. and Ghosal, N.G. (1982). Blood supply to the nasal cavity of sheep (ovis aries) and its significance to brain temperature regulation. Anat. Anz., 151: 14-28.

11. Khamas, W.A., Ghosal, N.G. and Bal, H.S. (1984). Histomorphologic structure of the carotid rete-cavernous sinus complex and its functional importance in sheep (ovis aries). Am. J. Vet. Res., 45: 156-158.

12. Lakshminarasimhan, A. (1974). Morphological variations of the sinus durae matris of the Indian buffalo (Bubalus bubalis). Anat.Histol.Embryol., 3: 57-62.

13. Miller, M.E., Christensen, G.C. and Evans, H.E. (1965). "Anatomy of the Dog". 2nd ed., W.B. Saunders Company, Philadelphia.

14. Nickel, R., Schummer, A. und Seiferle, E. (1975). "Lechbuch der Anatomie der Haustiere" Bd IV, Paul Barey, Berlin und Hamburg.

15. Uehara, M., Kudo, N. and Sugimura, M. (1978). Morphological studies on the rete mirable epidurale in the calf. Jpn. J. Vet. Res., 26: $11-18$.

16. Zguigal, H. and Ghoshal, N.G. (1991). Dural sinuses in the camel and their extracranial venous connections. Anat.Histol.Embryol., 20. 253-260.

17. Zguigal, H. and Ghoshal, N.G. (1991). Gross and histologic study of the rostral epidural rete mirable and the cavernous sinus in one-humped camels. Am.J.Vet.Res., 52:1173-1177. 